Scientia Agricola

http://dx.doi.org/10.1590/0103-9016-2015-0366

\title{
Survey of fungi associated with cassava root rot from different producing regions in
}

\section{Brazil}

Sandielle Araújo Vilas Boas ${ }^{1}$, Saulo Alves Santos de Oliveira², Carlos Augusto Dórea Bragança ${ }^{1}$, Juliana Barros Ramos ${ }^{1}$, Eder

Jorge de Oliveira ${ }^{2 *}$

${ }^{1}$ Federal University of Bahia Reconcavo - Center of Agricultural, Environmental and Biological Sciences, R. Rui Barbosa, 710 - 44380-000 - Cruz das Almas, BA - Brazil. ${ }^{2}$ Embrapa Cassava \& Fruits, R. Embrapa, $\mathrm{s} / \mathrm{n}-44380-000$

- Cruz das Almas, BA - Brazil.

*Corresponding author <eder.oliveira@embrapa.br>

Edited by: Emerson Medeiros Del Ponte

Received September 23, 2015

Accepted April 15, 2016
ABSTRACT: Although root rot is one of the major diseases affecting Brazilian cassava (Manihot esculenta Crantz.), little is known about the diversity of root rot pathogens. In this study, diseased plants exhibiting root rot symptoms were collected from cassava-producing regions in five Brazilian states: Bahia, Sergipe, Paraíba, Maranhão, Tocantins, and Paraná. Seventy isolates were obtained and assigned to species complexes based on rDNA's ITS (internal transcribed spacer of the ribosomal DNA) region (ITS1, ITS2 and 5.8S). A total of seven species complexes was found belonging to the genus Fusarium (56/74), followed by Lasiodiplodia (8/74), Neoscytalidium (6/74), and Diaporthe/Phomopsis complex (2/74), Phytophthora, and Corallomycetella (1/74 each). These species were distributed differently according to sample locations and states, but overall, the $F$. solani species complex (FSSC) was the most prevalent. A number of phylogenetic lineages had not been previously reported as being associated with cassava-root rot disease, such as: F. graminearum (FGSC), F. incarnatum-equiseti (FIESC) and F. chlamydosporum (FCSC) complexes, and a phylogenetic lineage most closely related to $P$. phaseolorum. Results suggest the need to improve knowledge of the species associated with cassava, including multilocus phylogeny for a more specific characterization, and differences in the resistance background associated with these species, as a strategy to incorporate resistance to multiple pathogens in cassava breeding programs.

Keywords: Manihot esculenta, ITS barcode, phylogeny, soil-borne diseases

\section{Introduction}

Cassava is a major source of carbohydrates for millions of people in several regions, particularly in developing countries. The cassava crop plays a vital role in reducing poverty and rural exodus because the use of technology required is minimal (Akinbo et al., 2012). In addition to the social impact, cassava has attracted the interest of the agriculture business due to its multiple industrial uses of starch (Tonukari, 2004).

In Brazil, different diseases affect cassava production, namely, root rot disease (CRRD), a major constraint responsible for up to $80 \%$ of losses in yield. Symptoms of CRRD vary according to the causal agent and can be divided into dry, soft, and black rot (Bandyopadhyay et al., 2006). In general, dry rot is characterized by the appearance of dark brown streaks in the roots with no aqueous aspect, while soft rot is characterized by the darkening of the affected tissues with liquid exudation and is foul-smelling. On the other hand, black rot is characterized by dark lesions (blackened) in the roots and stems and may evolve into soft rot but without the unpleasant odor.

The main pathogens associated with CRRD in Brazil are Fusarium spp. causing dry rot $(F$. solani, $F$. oxysporum, and F. verticillioides); Phytophthora spp. (P. nicotianae and $P$. drechsleri), Pythium scleroteichum, associated with soft rot, and Neoscytalidium hyalinum and Lasiodiplodia spp. causing black rot (Oliveira et al., 2013; Machado et al., 2014a). Knowledge of the diversity and geographical distribution of root rot pathogens may be useful to breeders targeting root rot resistance. This study aimed to identify the main species complex associated with cassava root rot samples in several regions in Brazil based on a phylogenetic approach.

\section{Materials and Methods}

Diseased roots and stems of cassava were collected from different producing regions in the states of Bahia (seven fields), Sergipe (two fields), Paraíba (one field), Maranhão (two fields), Tocantins (one field), and Paraná (two fields). Isolates were collected from 1991 to 2014, with the majority of the isolates being collected from 2012 to 2014 (Table 1). The sampled locations were chosen by information of CRRD outbreaks obtained from the plant disease clinic of Embrapa Cassava and Fruit and producers, and based on previous history of CRRD incidence in experimental and/or commercial areas.

In the laboratory, symptomatic tissues were cut into small pieces of approximately $0.5 \mathrm{~cm}$, dipped for 2 min in $70 \%$ ethanol, sterilized for $2 \mathrm{~min}$ in $0.5 \%$ sodium hypochlorite solution, and then washed with sterilized distilled water three times. The fragments were laid out to dry on sterile filter paper, and afterwards they were placed on potato dextrose agar (PDA) and incubated at $24^{\circ} \mathrm{C}$ for 5-7 days, for a 12 -h photoperiod.

The isolates of fungi and oomycetes obtained were grown in a specific medium to verify the morphology of 
Vilas Boas et al.

Survey of fungi associated with CRRD

Table 1 - Cassava root rot pathogens studied, with collection details and GenBank accession number for the ITS rDNA region.

\begin{tabular}{|c|c|c|c|c|}
\hline Voucher & Species/complex & Year & Location* & GenBank accession number \\
\hline CBPPR0002 & Corallomycetella repens & 2013 & Umbaúba-SE & KT211495 \\
\hline CBPPR2001 & DPMSC & 2013 & Cruz das Almas-BA & KT211565 \\
\hline CBPPR2002 & Diaporthe phaseolorum & 2013 & Cruz das Almas-BA & KT211566 \\
\hline CBPPR0008 & FCSC & 1991 & São Miguel das Matas-BA & KT211501 \\
\hline CBPPR0047 & FCSC & 2014 & Cruz das Almas-BA & KT211539 \\
\hline CBPPR0051 & FCSC & 2012 & Marechal Cândido Rondon-PR & KT211543 \\
\hline CBPPR0031 & FIESC & 2014 & Cruz das Almas-BA & KT211523 \\
\hline CBPPR0032 & FIESC & 2014 & Cruz das Almas-BA & KT211524 \\
\hline CBPPR0058 & FIESC & 2013 & Umbaúba-SE & KT211550 \\
\hline CBPPR0049 & FGSC & 2012 & Diamante do Norte-PR & KT211541 \\
\hline CBPPR0052 & FGSC & 2012 & Marechal Cândido Rondon-PR & KT211544 \\
\hline CBPPR0053 & FGSC & 2012 & Diamante do Norte-PR & KT211545 \\
\hline CBPPR0003 & FOSC & 2013 & Umbaúba-SE & KT211496 \\
\hline CBPPR0004 & FOSC & 2013 & Umbaúba-SE & KT211497 \\
\hline CBPPR0005 & FOSC & 2013 & Umbaúba-SE & KT211498 \\
\hline CBPPR0006 & FOSC & 1994 & São Miguel das Matas-BA & KT211499 \\
\hline CBPPR0007 & FOSC & 1990 & Ribeirópolis-SE & KT211500 \\
\hline CBPPR0010 & FOSC & 2013 & Cruz das Almas-BA & KT211503 \\
\hline CBPPR0011 & FOSC & 2013 & Cruz das Almas-BA & KT211504 \\
\hline CBPPR0013 & FOSC & 2013 & Cruz das Almas-BA & KT211506 \\
\hline CBPPR0017 & FOSC & 2013 & Cruz das Almas-BA & KT211510 \\
\hline CBPPR0019 & FOSC & 2013 & Cruz das Almas-BA & KT211512 \\
\hline CBPPR0021 & FOSC & 2013 & Cruz das Almas-BA & KT211513 \\
\hline CBPPR0028 & FOSC & 2013 & Cruz das Almas-BA & KT211520 \\
\hline CBPPR0035 & FOSC & 2007 & Vitória da Conquista-BA & KT211527 \\
\hline CBPPR0037 & FOSC & 2007 & Cachoeira-BA & KT211529 \\
\hline CBPPR0038 & FOSC & 2007 & Vitória da Conquista-BA & KT211530 \\
\hline CBPPR0039 & FOSC & 2007 & Ribeirópolis-SE & KT211531 \\
\hline CBPPR0041 & FOSC & 2008 & Guaratinga - BA & KT211533 \\
\hline CBPPR0043 & FOSC & 2013 & Cruz das Almas-BA & KT211535 \\
\hline CBPPR0054 & FOSC & 2012 & Diamante do Norte-PR & KT211546 \\
\hline CBPPR0055 & FOSC & 2012 & Diamante do Norte-PR & KT211547 \\
\hline CBPPR0056 & FOSC & 2013 & Umbaúba-SE & KT211548 \\
\hline CBPPR0015 & FFSC & 2013 & Cruz das Almas-BA & KT211508 \\
\hline CBPPR0048 & FFSC & 2012 & Cruz das Almas-BA & KT211540 \\
\hline CBPPR0001 & FSSC & 2013 & Umbaúba-SE & KT211494 \\
\hline CBPPR0009 & FSSC & 2013 & Cruz das Almas-BA & KT211502 \\
\hline CBPPR0012 & FSSC & 2013 & Cruz das Almas-BA & KT211505 \\
\hline CBPPR0014 & FSSC & 2013 & Cruz das Almas-BA & KT211507 \\
\hline CBPPR0016 & FSSC & 2013 & Cruz das Almas-BA & KT211509 \\
\hline CBPPR0018 & FSSC & 2013 & Cruz das Almas-BA & KT211511 \\
\hline CBPPR0022 & FSSC & 2013 & Cruz das Almas-BA & KT211514 \\
\hline CBPPR0023 & FSSC & 2013 & Cruz das Almas-BA & KT211515 \\
\hline CBPPR0024 & FSSC & 2013 & Cruz das Almas-BA & KT211516 \\
\hline CBPPR0025 & FSSC & 2013 & Cruz das Almas-BA & KT211517 \\
\hline CBPPR0026 & FSSC & 2013 & Cruz das Almas-BA & KT211518 \\
\hline CBPPR0027 & FSSC & 2013 & Cruz das Almas-BA & KT211519 \\
\hline CBPPR0029 & FSSC & 2013 & Cruz das Almas-BA & KT211521 \\
\hline CBPPR0030 & FSSC & 2013 & Texeira de Freitas-BA & KT211522 \\
\hline CBPPR0033 & FSSC & 2007 & Porto Seguro-BA & KT211525 \\
\hline CBPPR0034 & FSSC & 2007 & Humberto de Campos-MA & KT211526 \\
\hline CBPPR0036 & FSSC & 2007 & Axixá-MA & KT211528 \\
\hline CBPPR0040 & FSSC & 2008 & Guaratinga - BA & KT211532 \\
\hline CBPPR0042 & FSSC & 2008 & Cruz das Almas-BA & KT211534 \\
\hline
\end{tabular}

Continue... 
Vilas Boas et al.

Survey of fungi associated with CRRD

Table 1 - Continuation.

\begin{tabular}{|c|c|c|c|c|}
\hline CBPPR0044 & FSSC & 2014 & Cruz das Almas-BA & KT211536 \\
\hline CBPPR0045 & FSSC & 2013 & Texeira de Freitas-BA & KT211537 \\
\hline CBPPR0046 & FSSC & 2013 & Texeira de Freitas-BA & KT211538 \\
\hline CBPPR0050 & FSSC & 2012 & Marechal Cândido Rondon-PR & KT211542 \\
\hline CBPPR0057 & FSSC & 2013 & Umbaúba-SE & KT211549 \\
\hline CBPPR1002 & LTSC & 2014 & Cruz das Almas-BA & KT211551 \\
\hline CBPPR1003 & LTSC & 2014 & Cruz das Almas-BA & KT211552 \\
\hline CBPPR1004 & LTSC & 2014 & Cruz das Almas-BA & KT211553 \\
\hline CBPPR1005 & LTSC & 2014 & Cruz das Almas-BA & KT211554 \\
\hline CBPPR1006 & LTSC & 2012 & Palmas-TO & KT211555 \\
\hline CBPPR1007 & LTSC & 2012 & Palmas-TO & KT211556 \\
\hline CBPPR1008 & LTSC & 2012 & Palmas-TO & KT211557 \\
\hline CBPPR1009 & LTSC & 2012 & Palmas-TO & KT211558 \\
\hline CBPPR1001 & Neoscytalidium hyalinum & 1996 & Areias-PB & KT211559 \\
\hline CBPPR1011 & N. hyalinum & 2007 & Humberto de Campos-MA & KT211560 \\
\hline CBPPR1012 & N. hyalinum & 2007 & Areias-PB & KT211561 \\
\hline CBPPR1014 & N. hyalinum & 2007 & Axixá-MA & KT211562 \\
\hline CBPPR1015 & N. hyalinum & 2012 & Cruz das Almas-BA & KT211563 \\
\hline CBPPR1016 & N. hyalinum & 2012 & Cruz das Almas-BA & KT211564 \\
\hline CBPPR3001 & Phytophthora melonis & 2014 & Cruz das Almas-BA & KT211567 \\
\hline
\end{tabular}

DPMSC: Diaporthe (Phomopsis) melonis species complex; FCSC: F. chlamydosporum species complex; FIESC: F. incarnatum-equiseti species complex; FGSC: F. graminearum species complex; FOSC: F. oxysporum species complex; FFSC: F. fujikuroi species complex; FSSC: Fusarium solani species complex; LTSC: Lasiodiplodia theobromae species complex. ${ }^{\star}$ States from the Northeast region of Brasil: BA: Bahia; MA: Maranhão; PB: Paraiba; SE: Sergipe. ${ }^{\star}$ State from the Northern region of Brasil: TO: Tocantins. * State from the South region of Brasil: PR: Paraná.

spores and mycelia, PDA + pine acicula for fungi and 'carrot agar' + Beta-sitosterol for oomycetes. Isolates were grouped, based on the morphology of the colony and spores, and then the cassava-root slices /Onyeka et al., 2005b) were inoculated to confirm pathogenicity. Monosporic cultures were preserved in tubes with culture medium according to the Castellani method and with mineral oil. Only those isolates considered as pathogenic, based on the cassava root-slice inoculation, were used in this study.

\section{DNA extraction}

Monosporic cultures of each isolate of fungi and oomycetes were placed to grow in sucrose and yeast extract broth (10 g sucrose, 2 g yeast extract, $1 \mathrm{~g} \mathrm{KH}_{2} \mathrm{PO}_{4}$ $0,1 \mathrm{~g} \mathrm{MgSO}_{4} \cdot 7 \mathrm{H}_{2} \mathrm{O}, 0.44 \mathrm{mg}$ of $\mathrm{ZnSO}_{4} \cdot 7 \mathrm{H}_{2} \mathrm{O}$, and 1000 $\mathrm{mL}$ distilled water) for 15 days, and then the mycelium was filtered, arranged so as to dry out, and then macerated with liquid nitrogen and mixed with $700 \mu$ extraction buffer $(1 \%$ CTAB, 20 mM Tris, $\mathrm{pH} 8.0 ; 10 \mathrm{mM}$ EDTA; $0.7 \mathrm{M} \mathrm{NaCl}$ ) and $10 \mu \mathrm{L}$ of $\beta$-mercaptoethanol). The mixture was kept at $65^{\circ} \mathrm{C}$ for $45 \mathrm{~min}$ and homogenized gently every $15 \mathrm{~min}$. Subsequently, $500 \mu \mathrm{L}$ of Chloroform:Isoamyl Alcohol (24:1 v/v) was added, and the mixture was centrifuged for $10 \mathrm{~min}$ at 10,000 rpm. Supernatant was transferred to a new tube containing $500 \mu \mathrm{L}$ of isopropanol and $100 \mu \mathrm{L}$ of sodium acetate and was centrifuged at 10,000 rpm for $12 \mathrm{~min}$.

Finally, the precipitate was washed twice with 1 $\mathrm{mL}$ of $70 \%$ ethanol, placed so as to dry at room temperature, resuspended with Tris-EDTA buffer (TE) (10 $\mathrm{mM}$ Tris-HCL $+1 \mathrm{mM}$ EDTA) and $2 \mu \mathrm{L}$ of ribonuclease
A [RNAse] $\left(10 \mathrm{mg} \mathrm{mL}^{-1}\right)$, and incubated at $37{ }^{\circ} \mathrm{C}$ for $1 \mathrm{~h}$. After extraction, the solution containing DNA was stored at $-20{ }^{\circ} \mathrm{C}$. The quality and quantity of total DNA was measured by visual comparison with phage $\lambda$ DNA at concentrations of 50 and $100 \mathrm{ng}$ electrophoreses in agarose gel (1\% 80V $\left.60 \mathrm{~min}^{-1}\right)$ stained with ethidium bromide $\left(1.5 \mu \mathrm{L} 100 \mathrm{~mL}^{-1}\right)$.

\section{Amplification and sequencing}

Amplification of the ITS region of the rDNA from isolates was performed using the universal primers ITS1 (5'TCC GTA GGT GAA CCT GCG G3') and ITS4 (5'TCC TCC GCT TAT TGA TAT GC3'). In $200 \mu \mathrm{L}$ microtubes the following was added: $50 \mathrm{ng}$ DNA; $1 \mathrm{X}$ Tris$\mathrm{HCl} / \mathrm{KCl} \mathrm{pH} 8.3$ (10 mM / $50 \mathrm{mM}) ; \mathrm{MgCl}_{2}$ (1.5 mM); $0.1 \mu \mathrm{M}$ of each dNTP; $0.2 \mu \mathrm{M}$ of each primer; $1.5 \mathrm{U}$ Taq polymerase, and ultrapure water to complete the volume of $50 \mu \mathrm{L}$. The reactions consisted of an initial denaturation phase at $94{ }^{\circ} \mathrm{C}$ for $4 \mathrm{~min}$, followed by 35 cycles at $94{ }^{\circ} \mathrm{C}$ for $30 \mathrm{~s}, 30 \mathrm{~s}$ annealing at $50{ }^{\circ} \mathrm{C}$, extension at $72{ }^{\circ} \mathrm{C}$ for $1 \mathrm{~min}$, and a final extension of $72{ }^{\circ} \mathrm{C}$ for $7 \mathrm{~min}$. Amplification was performed in a 96-Well Thermal Cycler.

The amplified products in the reaction were separated by agarose gel electrophoresis at $1 \%$ to $100 \mathrm{~V}$ in 0.5X TAE buffer (Tris-acetate-EDTA) for approximately $2 \mathrm{~h}$ and stained with ethidium bromide solution $1.5 \mu \mathrm{L}$ $100 \mathrm{~mL}^{-1}$. The amplified fragments were visualized and photographed under ultraviolet light. The PCR reaction products were purified by a commercial column purification kit and then sent for sequencing in two directions (forward and reverse). 
The DNA sequences obtained were evaluated for sequencing quality, aligned pair-to-pair, and manually edited to obtain a consensus sequence for each isolate. The consensus sequences generated were compared with those deposited in the GenBank (National Center for Biotechnology Information website - http://www. ncbi.nlm.nih.gov) through the BLASTn tool for confirmation of the genus of each of the isolates. The verification of the identity of the species causing CRRD was carried out using phylogenetic analyses of Neighbor-Joining (NJ) and Bayesian inference, and was compared to reference sequences deposited in the Genbank.

\section{Phylogenetic analyses}

The rDNA ITS regions (comprising the ITS1, 5.8S and ITS2) were aligned with isolates from different species complexes using the "Muscle" algorithm implemented in the software MEGA v.6. Although the ITS may not be appropriate for accurate identification of strains at the species level, it can be used to classify them into species complexes. In the alignment matrices, sequences from the GenBank database were included based on index similarity. Outgroups used for each genus were Microdochium nivale - CBS 116205 (Fusarium), Spencermartinsia viticola - CBS 117009 (Lasiodiplodia and Neoscytalidium), Pythium citrinum - 221743 (Phytophthora), Diaporthella corylina - CBS 121124 (Phomopsis).

Phylogenetic analyses based on NJ were performed using MEGA v.6 with a "Kimura 2-parameter" model and 10,000 bootstrap replicates to determine the support of the branches. For the Bayesian inference analysis, the evolution model for each genus was chosen using hierarchical likelihood tests considering the Akaike Information Criterion (AIC) using the MrModeltest v.2.3 program. The consensus trees were generated using the MrBayes software v.3.2, with 5,000,000 generations (convergence 0.001) through two independent runs; each used four Markov Monte Carlo Chains (MCMC), two hot and two cold chains, sampling a tree every 1,000 generations, and burn-in of the initial 1,250,000 generations. The trees were visualized and edited using the FigTree software v.1.2.2.

\section{Results}

From a total of 115 isolates obtained from diseased cassava plants, only the 74 considered as pathogenic were used. These isolates were obtained from different producing regions (Table 1). Isolates were separated based on the genus defined by BLAST search in the GenBank database (National Center for Biotechnology Information) and phylogenetic analyses. The most frequent species were of the genus Fusarium (56), followed by Lasiodiplodia (8), Neoscytalidium (6), and Diaporthe/Phomopsis complex (2), Phytophthora and Corallomycetella (1 each).

According to the phylogenetic analysis of ITS rDNA region, the Fusarium-like isolates, associated with dry root-rot symptoms, were divided into six groups (Figure 1). Five of them had more than one isolate per group, and one group had a single isolate. 'Group 1' (F. solani species complex - FSSC) comprised a total of 24 isolates which were clustered and divided into three clusters inside the FSSC, but all considered as F. solani sensu lato (Table 1).

For the isolates clustered in 'Group 2' $(F$. oxysporum species complex - FOSC) (Figure 1), a high posterior probability was found (0.92). This indicated that 21 of the isolates represented lineages of FOSC, from this 15 were from crops in the state of Bahia, six were from Sergipe, and two were from Paraná, corresponding to $50 \%$ of the states sampled.

'Group 3' was composed of six isolates each grouped into $F$. incarnatum-equiseti (FIESC) and F. chlamydosporum (FCSC) complexes (Figure 1). In contrast, 'Group 4' was composed of three isolates belonging to F. graminearum complex (FGSC), and two isolates were placed in 'Group 5' with species from $F$. fujikuroi complex (FFSC). In Group 6 an isolate relating to the species Corallomycetella repens (teleomorph $=$ Nectria mauritiicola) was identified.

Seven lineages associated with dry root rot symptoms with different frequencies were identified: FSSC (24/56), FOSC (21/56), FGCS (3/56), FCSC (3/56), FIESC (3/56), FFSC (2/56), plus one isolate characterized as Corallomycetella repens (teleomorph $=$ Nectria mauritiicola) and not Fusarium (Figure 1).

A total of 15 isolates associated with black root rot were classified within the Botryosphaeriaceae family, being nine isolates clustered as Lasiodiplodia theobromae species complex and six isolates were identified as Neoscytalidium hyalinum (Figure 2), originating from the states of Bahia, Maranhão, Paraiba and Tocantins.

Two of the strains obtained showed a high similarity to Phomopsis sp. in a BLASTn search. These sequences came from fields located in the state of Bahia and the city of Cruz das Almas. According to phylogenetic analysis of ITS-barcoding, they were clustered in a single clade within the Diaporthe/Phomopsis complex (posterior probability $=0.63$ ), and the CBPPR2001 isolate had a $99 \%$ identity to Diaporthe (Phomopsis) phaseolorum (Figure 3A). The CBPPR2002 isolate was set in a different branch in the same clade, but it was not possible to determine the species to which it belonged because additional molecular sequences from other regions would have been required.

The CBPPR3001 isolate was obtained in the state of Bahia (Cruz das Almas), causing soft root rot symptoms, and was grouped together with the species P. melonis (99\% similarity), according to the phylogenetic analysis based on the ITS region of rDNA (Figure 3B).

The same tree topology was obtained for all phylogenetic analyses based on the NJ and Bayesian inference, for all genera evaluated. 


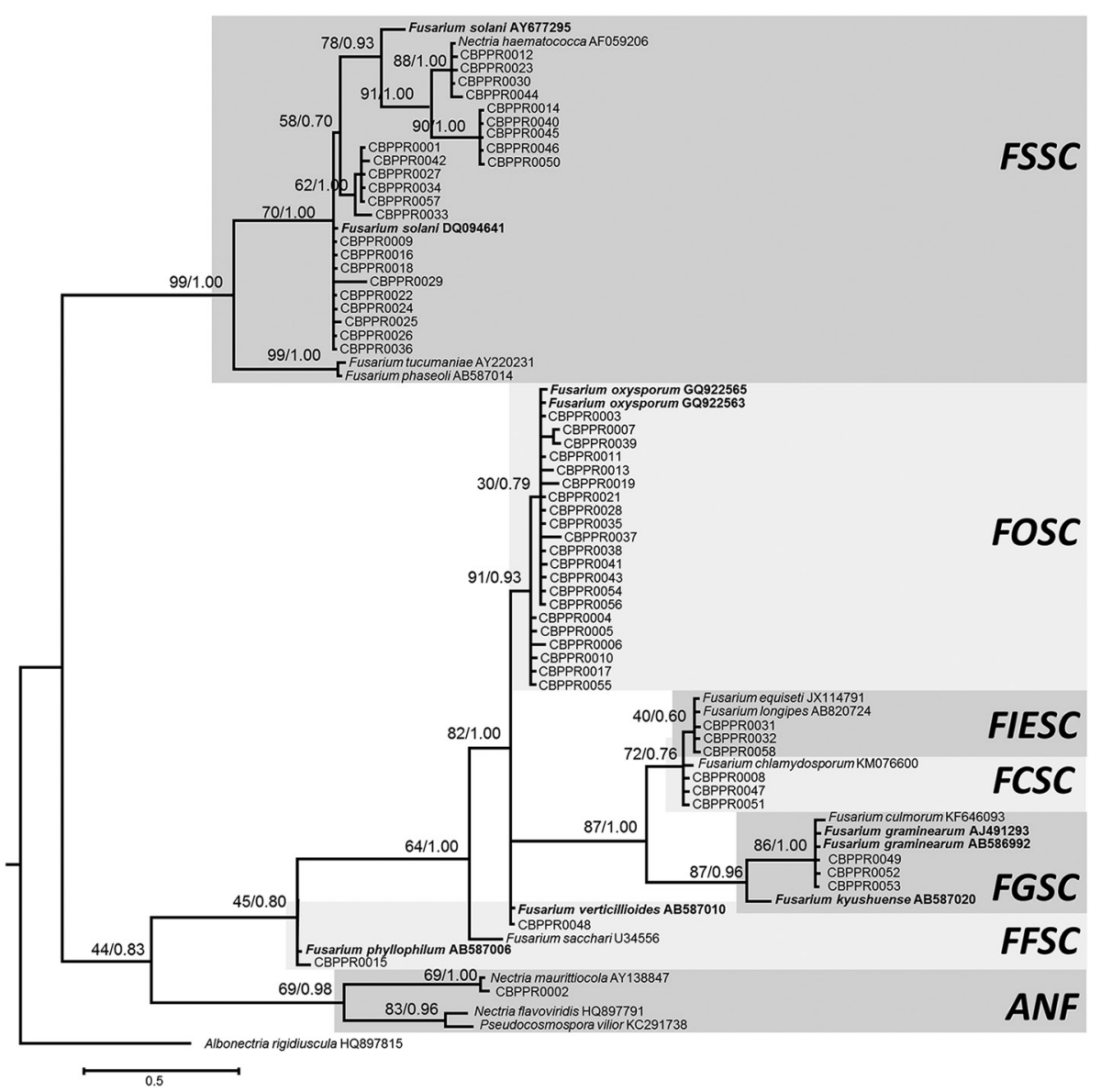

Figure 1 - A Bayesian inference phylogenetic tree of the genus Fusarium of the ITS rDNA region. Bootstrap values $\geq 50$ and Bayesian posterior probability $\geq 0.5$ are shown at the nodes (Neighbor Joining/Bayesian). Ex-type cultures are emphasized in bold font. Microdochium nivale (AB58698) was used as outgroup. The scale bar indicates the number of expected changes per site. FSSC = Fusarium solani species complex; FOSC $=$ F. oxysporum species complex; FIESC $=$ F. incarnatum-equiseti species complex; FCSC = F. chlamydosporum species complex; FGSC $=F$. graminearum species complex; FFSC $=$ F. fujikuroi species complex; ANF = species where the "Anamorph is not Fusarium". Isolates beginning with "CBPPR" are from this study.

\section{Discussion}

Isolates in F. solani (FSSC) and F. oxysporum (FOSC) complexes are often reported as the most prevalent associated with CRRD, FSSC being the most widely distributed among the different producing regions worldwide. Fusarium solani sensu lato was also reported as a cassava pathogen in Colombia. Based on morphological characteristics, this fungus is considered to be more common than the $F$. oxysporum as a causal agent of CRRD /Onyeka et al., 2005a).

FSSC and FOSC showed a frequency of $45 \%$ in a survey of pathogens occurring in Nigeria in 1998 and 1999. They occurred more frequently in areas with more than 1,600 mm of rain per year (Bandyopadhyay et al., 2006). In addition to Colombia, F. solani has also been reported in association with cassava in India, Malaysia, Nigeria, and New Guinea (Adisa, 1983; Shaw, 1984; Cheari et al., 2014.). In fact, in several African countries, different Fusarium spp. are commonly associated with cassava root rot disease. The $F$. oxysporum is one of the most widespread species and is associated with large losses in the productivity of cassava (Bandyopadhyay et al., 2006).

C. repens is a saprophytic species, but it can also be parasitic in plant roots. Generally, this is a problem in soils with drainage problems, causing yellowing and leaves with decay accompanied by a bad odor (Seifert, 1985). Another synonym of C. repens is Sphaerostilbe repens, which has also been observed in African countries causing CRRD (Obilo and Ikotun, 2008).

The species $L$. theobromae has been described previously in cassava in different countries, but other species are also found in cassava fields associated with CRRD, such as L. parva L. pseudotheobromae, and L. euphorbicola (Marques et al., 2013; Machado et al., 2014a; Machado et al., 2014b; Netto et al., 2014). As a consequence of the high genetic identity (> $78 \%$ ) among dif- 


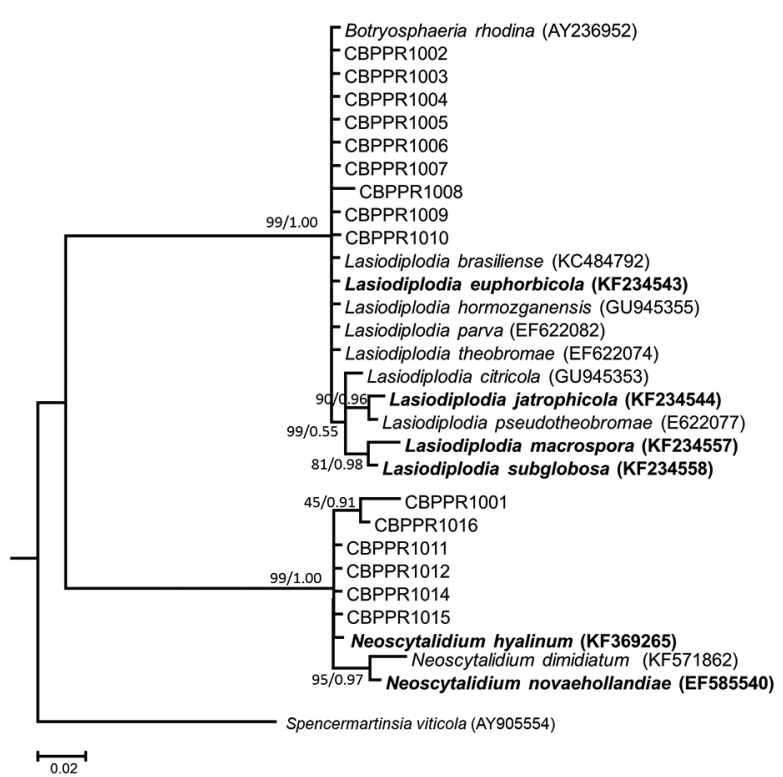

Figure 2 - A Bayesian inference phylogenetic tree of the family Botryosphaeriaceae of the ITS rDNA region. Bootstrap values $\geq 40$ and Bayesian posterior probability $\geq 0.5$ are shown at the nodes (Neighbor Joining/Bayesian). Ex-type strains are emphasized in bold font. Spencermartinsia viticola (AY905554) was used as outgroup. The scale bar indicates the number of expected changes per site. Isolates beginning with "CBPPR" are from this study.

ferent species and the isolates classified in this work as $L$. theobromae, additional studies should be conducted to more assertively identify the species found through polyphasic characterization, including the sequencing of other genetic regions such as the elongation factor alpha (EF1- $\alpha$ ) and beta tubulin ( $\beta \mathrm{t})$.

The name Scytalidium lignicola is applied to certain pathogens causing cassava root rot in Brazil (Machado et al., 2014a). However, several species of Scytalidium are now classified under the genus Neoscytalidium, whose morphology is similar to Scytalidium but differs in the presence or absence of pycnidia and conidia between genera and belongs to different orders of Ascomycota (Crous et al., 2006; Seifert et al., 2011; Phillips et al., 2013; Machado et al., 2014a).

The species $N$. hyalinum previously classified as Neoscytalidium dimidiatum refers to a Botryosphaeriaceae fungus family, which includes several pathogenic fungi, endophytes, and saprophytes found in all geographic and climatic areas of the world, except for the polar regions (Crous et al., 2006; Phillips et al., 2013). N. hyalinum has previously been reported in association with physic nut (Jatropha curcas L.), mango (Mangifera indica L.), and cassava in Brazil (Machado et al., 2012; Marques et al., 2013; Machado et al., 2014a; Machado et al., 2014b).

The Diaporthe genus includes plant pathogenic species in many woody and herbaceous hosts that are found mainly in its anamorphic state Phomopsis. Many
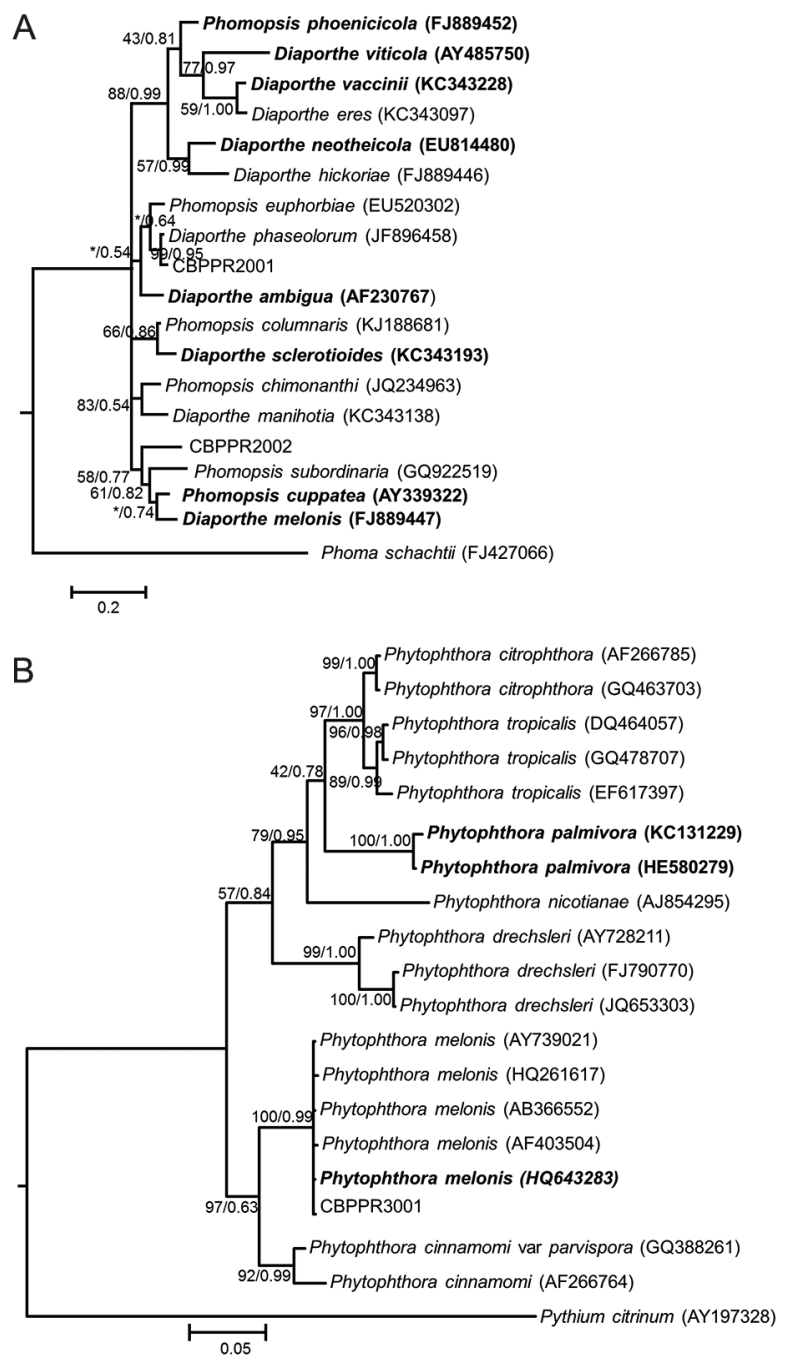

Figure 3 - A Bayesian inference phylogenetic tree of the Diaporthe/ Phomopsis complex (A) and Phytophthora (B) of the ITS rDNA region. Bootstrap values $\geq 40$ and Bayesian posterior probability $\geq$ 0.5 are shown at the nodes (Neighbor Joining/Bayesian). Ex-type strains are emphasized in bold font. Phoma schachtii (FJ427066) and Pythium citrinum (AY197328) were used as outgroup, for $A$ and $B$ respectively. The scale bar indicates the number of expected changes per site. Isolates beginning with "CBPPR" are from this study.

of its species cause major losses to infected plants of economic interest such as fruit, and cause cancers, rot, diebacks, and necrosis, among other pathologies. These fungi can survive as endophytes, without causing any damage to the host, and they may become pathogenic when the host is senescent or under stress conditions; there are a lot of species with saprophytic behavior.

Examples of pathogens are P. amygdali (Delacr.) JJ Tuset \& MT Portilla, which are responsible for stem discoloration and death of peach (Farr et al., 1999), D. helianthi Munt.-Cvetk., Mihalj . \& M. Petrov, that cause Pho- 
mopsis stem canker in sunflower (Muntanola-Cvetkovic et al., 1991), D. phaseolorum (Cooke and Ellis) Sacc., which is the causal agent of soybean stem canker (Black et al., 1996), and P.viticola (Sacc.) Sacc., is an important pathogen of grape (Mostert et al., 2001). However, even though $D$. phaseolorum is a notorious rot and stem pathogen in other plant species, this is the first report of its kind associated with CRRD.

Species of the genus Phytophthora have been associated with soft root rot in cassava such as $P$. palmivora, which was recently reported to have attacked cassava plants in China and whose symptoms were characterized by widespread wilting in the upper leaves and death of the plant (Guo et al., 2012). In Brazil, P. drechsleri and $P$. melonis species have also been associated with CRRD, and $P$. drechsleri is considered the main causal agent of soft root rot.

Species of the genus Fusarium were found in almost all locations sampled, except for Areia, the state of Paraíba and Palmas, and the state of Tocantins, where the species $N$. hyalinum and $L$. theobromae were predominant, respectively. Therefore, in general, there was a wide distribution of Fusarium species. On the other hand, different compositions of species were found, in some cases restricted to a geographical region such as the occurrence of species of the complex $F$. graminearum in the municipalities of the state of Paraná (Diamante do Norte and Marechal Cândido Rondon).

Fungi that cause black root rot disease such as $N$. hyalinum and $L$. theobromae were mainly identified in the municipalities in the north and northeast of Brazil. According to Aigbe et al. (2008), there is an association between species causing root rot and edaphoclimatic parameters as well as the stage of development of the culture, and in the early stages of plant development there is a common occurrence of Fusarium species, while in the later stages, there is a predominance of black rot pathogens.

CRRD is difficult to manage because is caused by a complex of soil-borne fungi/oomycete species, which makes chemical control infeasible due to environmental damage and its high treatment costs for producers. These limitations require the identification of alternative ways to managing the disease including sustainable practices that are more accessible to farmers and less harmful to the environment. Different studies showed that the use of resistant varieties, together with crop rotation and changes in the cropping systems, enabled a reduction of about $60 \%$ in CRRD (Bezerra and Sousa, 2003) and contribute significantly to increasing productivity, thus improving the quality and the aspect of cassava, and obtaining a better final product.

Data from this study support the need for a deeper understanding of the genetic resistance of cassava accessions in germplasm banks. Likewise, they indicate the need for evaluation based on observation of the reaction of cassava genotypes from different species of pathogens individually and based not only on observations in the field, since the pathogens can vary according to location. Problems related to the selection of plants resistant to CRRD were reported by Bandyopadhyay et al. (2006), who considered that the geographical differences related to the diversity of the populations of root rot fungi pose a challenge to the genetic improvement since that genotypes considered resistant in one region may not be in another.

Thus, because of the diversity of lineages found in this study, breeding programs must include selection for multiple resistant cassava root rot pathogens, mainly for the FSSC and FOSC and for the isolates associated with black root rot (Lasiodiplodia spp. and Neoscytalidium hyalinum lineages), either in individual evaluations (each species complex versus each of access) or by directly challenge by different groups of pathogens (e.g.: dry and black root rot pathogens). Consequently, the results obtained in this study will be used to conduct experiments aiming to select genotypes resistant to cassava root rot disease through the cassava breeding program, and for other Brazilian research companies and/or universities.

\section{Acknowledgements}

We are grateful to the Brazilian Agricultural Research Corporation (Embrapa), National Council for Scientific and Technological Development (CNPq), and The Bahia State Research Support Foundation (Fapesb) for financial support of this project and to the office of the Coordination for the Improvement of Higher Level Personnel (CAPES) for the fellowship (Master Degree) of Sandielle Araújo Vilas Boas.

\section{References}

Adisa, V.A. 1983. Surface mycoflora of Manihot esculenta and $M$. utilissima tubers in Nigeria. Indian Phytopathology 36: 533-538.

Akinbo, O.; Labuschagne, M.; Fregene, M. 2012. Introgression of whitefly (Aleurotrachelus socialis) resistance gene from $\mathrm{F}_{1}$ interspecific hybrids into commercial cassava. Euphytica 183: 19-26.

Bandyopadhyay, R.; Mwangi, M.; Aigbe, S.O.; Leslie, J.F. 2006. Fusarium species from the cassava root rot complex in West Africa. Phytopathology 96: 673-676.

Black, B.D.; Padgett, G.B.; Russin, J.S.; Griffin, J.L.; Snow, J.P.; Gerggren, J.R.G.T. 1996. Potential weed hosts for Diaporthe phaseolorum var. caulivora, causal agent for soybean stem canker. Plant Disease 80: 763-765.

Cheari, K.; Salleh, B.; Zakaria, L. 2014. Fusarium virguliforme, a soybean sudden death syndrome fungus in Malaysian soil. Australasian Plant Disease Notes 9: 1-7.

Crous, P.W.; Slippers, B.; Wingfield, M.J.; Rheeder, J.; Marasas, W.F.O.; Phillips, A.J.L.; Alves, A.; Burgess, T.; Barber, P.; Groenewald, J.Z. 2006. Phylogenetic lineages in the Botryosphaeriaceae. Studies in Mycology 55: 235-253.

Farr, D.F.; Castlebury, L.A.; Pardo-Schultheiss R.A. 1999. Phomopsis amygdale causes peach shoot blight of cultivated peach trees in the southeastern United States. Mycologia 91: 1008-1015. 
Guo, H.; Li, C.P.; Shi, T.; Fan, C.J.; Huang, G.X. 2012. First report of Phytophthora palmivora causing root rot of cassava in China. Plant Disease 96: 1072.

Machado, A.R.; Pinho, D.B.; Dutra, D.C.; Pereira, O.L. 2012. Collar and root rot caused by Neoscytalidium dimidiatum in the biofuel plant Jatropha curcas. Plant Disease 96: 1697.

Machado, A.R.; Pinho, D.B.; Oliveira, S.A.S.; Pereira, O.L. 2014a. New occurrences of Botryosphaeriaceae causing black root rot of cassava in Brazil. Tropical Plant Pathology 39: 464-470.

Machado, A.R.; Pinho, D.B.; Pereira, O.L. 2014b. Phylogeny, identification and pathogenicity of the Botryosphaeriaceae associated with collar and root rot of the biofuel plant Jatropha curcas in Brazil, with a description of new species of Lasodiplodia. Fungal Diversity 67: 231-247.

Marques, M.W.; Lima, N.B.; Morais, J.R.M.A.; Barbosa, M.A.G.; Souza, B.O.; Michereff, S.J.; Phillips, A.J.L.; Câmara, M.P.S 2013. Species of Lasiodiplodia associated with mango in Brazil. Fungal Diversity 61: 181-193.

Mostert, L.; Crous, P.W.; Kang, J.C.; Phillips, A.J.L. 2001. Species of Phomopsis and a Libertella sp. occurring on grapevines with specific reference to South Africa: morphological, cultural, molecular and pathological characterization. Mycologia 93: 146-167.

Muntanola-Cvetkovic, M.; Vukojevic, J.; Mihaljčevic, M. 1991. The systemic nature of the sunflower disease caused by Diaporthe helianthi. Canadian Journal of Botany 69: 1552-1556.

Netto, M.S.B.; Assunção, I.P.; Lima, G.S.A.; Marques, M.W.; Lima W.G.; Monteiro, J.H.A.; Balbino, V.Q.; Michereff, S.J.; Phillips, A.J.L.; Câmara, M.P.S. 2014. Species of Lasiodiplodia associated with papaya stem-end rot in Brazil. Fungal Diversity 67: 127141.
Obilo, O.P.; Ikotun B. 2008. Effect of canker size on availability of cassava planting materials in Nigeria. African Crop Science Journal 16: 203-209.

Onyeka, T.J.; Dixon, A.G.O.; Ekpo, E.J.A. 2005a. Field evaluation of root rot disease and relationship between disease severity and yield in cassava. Experimental Agriculture 41: 357-363.

Onyeka, T.J.; Dixon, A.G.O.; Ekpo, E.J.A. 2005b. Identification of levels of resistance to cassava root rot disease (Botryodiplodia theobromae) in African landraces and improved germplasm using in vitro inoculation method. Euphytica 145: 281-288.

Phillips, A.J.L.; Alves, A.; Abdollahzadeh, J.; Slippers, B.; Wingfield, M.J.; Groenewald, J.Z.; Crous, P.W. 2013. The Botryosphaeriaceae: genera and species known from culture. Studies in Mycology 76: 51-167.

Seifert, K.A.; Morgan-Jones, G.; Kendrick, W.B.; Gams, W. 2011. The genera of hyphomycetes. CBS-KNAW, Utrecht, The Netherlands.

Seifert, K.A. 1985. A monograph of Stilbella and some allied Hyphomycetes. Studies in Mycology 27: 1-235.

Shaw, D.E. 1984. Microorganisms in Papua New Guinea. Research Bulletin of the Department of Primary Industries Port Moresby 3: 1-344.

Tonukari, N.J. 2004. Cassava and the future of starch. Biotechnology Issues for Developing Countries 7: 5-8. 